\title{
Trial-based cost-effectiveness analysis of toric versus monofocal intraocular lenses in cataract patients with bilateral corneal astigmatism in the Netherlands
}

Citation for published version (APA):

Simons, R. W. P., Visser, N., van den Biggelaar, F. J. H. M., Nuijts, R. M. M. A., Webers, C. A. B., Bauer, N. J. C., Beckers, H. J. M., \& Dirksen, C. D. (2019). Trial-based cost-effectiveness analysis of toric versus monofocal intraocular lenses in cataract patients with bilateral corneal astigmatism in the Netherlands. Journal of Cataract and Refractive Surgery, 45(2), 146-152. https://doi.org/10.1016/j.jcrs.2018.09.019

Document status and date:

Published: 01/02/2019

DOI:

10.1016/j.jcrs.2018.09.019

Document Version:

Publisher's PDF, also known as Version of record

Document license:

Taverne

Please check the document version of this publication:

- A submitted manuscript is the version of the article upon submission and before peer-review. There can be important differences between the submitted version and the official published version of record.

People interested in the research are advised to contact the author for the final version of the publication, or visit the DOI to the publisher's website.

- The final author version and the galley proof are versions of the publication after peer review.

- The final published version features the final layout of the paper including the volume, issue and page numbers.

Link to publication

\footnotetext{
General rights rights.

- You may freely distribute the URL identifying the publication in the public portal. please follow below link for the End User Agreement:

www.umlib.nl/taverne-license

Take down policy

If you believe that this document breaches copyright please contact us at:

repository@maastrichtuniversity.nl

providing details and we will investigate your claim.
}

Copyright and moral rights for the publications made accessible in the public portal are retained by the authors and/or other copyright owners and it is a condition of accessing publications that users recognise and abide by the legal requirements associated with these

- Users may download and print one copy of any publication from the public portal for the purpose of private study or research.

- You may not further distribute the material or use it for any profit-making activity or commercial gain

If the publication is distributed under the terms of Article $25 \mathrm{fa}$ of the Dutch Copyright Act, indicated by the "Taverne" license above, 


\title{
Trial-based cost-effectiveness analysis of toric versus monofocal intraocular lenses in cataract patients with bilateral corneal astigmatism in the Netherlands
}

\author{
Rob W.P. Simons, MD, Nienke Visser, $M D$, PhD, Frank J.H.M. van den Biggelaar, PhD, \\ Rudy M.M.A. Nuijts, MD, PhD, Carroll A.B. Webers, MD, PhD, Noel J.C. Bauer, MD, PhD, \\ Henny J.M. Beckers, MD, PhD, Carmen D. Dirksen, PhD
}

Purpose: To evaluate the cost-effectiveness of toric versus monofocal intraocular lens (IOL) implantation in cataract patients with bilateral corneal astigmatism.

Setting: Two ophthalmology clinics in the Netherlands.

Design: Prospective cost-effectiveness analysis.

Methods: Resource-use data were collected over a 6-month postoperative period. Consecutive patients with bilateral agerelated cataract and 1.25 diopters or more of corneal astigmatism were included in the economic evaluation. Patients were randomized to phacoemulsification with bilateral toric or monofocal IOL implantation. All relevant resources were included in the cost analysis. The base-case analysis was performed from a societal perspective based on quality-adjusted life years (QALYs). The main outcome was the incremental cost-effectiveness ratio.
Results: The analysis comprised 77 consecutive patients (33 toric IOL; 44 monofocal IOL). Societal costs were higher in the toric IOL group (€3203 [\$3864]) than in the monofocal IOL group (€2796 [US\$3373]). QALYs were slightly lower in the toric IOL group ( 0.30 versus $0.31 ; P=.75)$. Toric IOLs were therefore inferior to monofocal IOLs from a cost-effectiveness perspective. The costeffectiveness probability ranged from $1 \%$ to $15 \%$, assuming a ceiling ratio for the incremental cost-effectiveness ratio of $€ 2500$ to $€ 20000$ per QALY.

Conclusions: From a societal perspective, bilateral toric IOL implantation in cataract patients with corneal astigmatism was not cost-effective compared with monofocal IOL implantation. Copayment by patients should therefore be considered.

J Cataract Refract Surg 2019; 45:146-152 @ 2018 ASCRS and ESCRS
( ompared to standard monofocal IOL implantation, implantation of toric intraocular lenses (IOLs) during cataract surgery improves uncorrected distance visual acuity (UDVA) and distance spectacle independence in cataract patients with corneal astigmatism. ${ }^{1-6}$ Toric IOL implantation in eyes with astigmatism as low as 0.75 to 1.50 diopters (D) results in significantly better postoperative UDVA than monofocal IOL implantation. ${ }^{2,3}$
Spectacle independence after cataract surgery is associated with better patient satisfaction and vision-related quality of life and lower long-term spectacle costs. ${ }^{5-10}$ However, toric IOLs are more costly than monofocal IOLs and implantation of toric IOLs requires more surgery time. This increases short-term healthcare costs. ${ }^{7}$ Considering the vast number of patients eligible for toric IOLs and the potential impact on national healthcare budgets, a

Submitted: February 2, 2018 | Final revision submitted: July 5, 2018 | Accepted: September 3, 2018

From the University Eye Clinic Maastricht (Simons, Visser, van den Biggelaar, Nuijts, Webers, Bauer, Beckers) and the Department of Clinical Epidemiology and Medical Technology Assessment (Dirksen), CAPHRI School for Public Health and Primary Care, Maastricht University Medical Centre+, Maastricht, the Netherlands.

Presented at the annual meeting of the Netherlands Ophthalmological Society, Groningen, the Netherlands, April 2016, and at the XXXIV Congress of the European Society of Cataract and Refractive Surgeons, Copenhagen, Denmark, September 2016.

Supported by the Ministry of Health, Welfare, and Sport and the Netherlands Organisation for Health Research and Development (grant 171001011). The funding organization was not involved in any part of the study design and conduct; collection, management, analysis, and interpretation of the data; preparation, review, or approval of the manuscript; or decision to submit the manuscript for publication.

Sander M.J. van Kuijk, PhD, Department of Clinical Epidemiology and Medical Technology Assessment, Maastricht University Medical Center +, assisted with the statistical analyses.

Corresponding author: Rob W.P. Simons, MD, University Eye Clinic Maastricht, Maastricht University Medical Centre+, PO Box 5800 , 6202 AZ Maastricht, the Netherlands. Email: rob.simons@mumc.nl. 
cost-effectiveness analysis is required to aid health policymakers in making evidence-based decisions on the allocation of scarce healthcare resources.

Quality-adjusted life years (QALYs) are the preferred measure for assessing the benefit of health interventions in economic evaluations because they can be applied in all fields of healthcare to compare different types of healthcare interventions in different populations. Using the cost per QALY, health policymakers can allocate limited healthcare resources based on a predefined willingness to pay per QALY. Calculation of QALYs is based on the measurement of generic health-related quality of life (HRQL) over a predefined period. ${ }^{11}$

Previous cost-effectiveness analyses of toric IOLs have been reported. Pineda et al. ${ }^{7}$ developed a decision analytic model and found that lifetime cost savings were US $\$ 349$ per QALY gained. However, QALYs were not determined according to standard methods. ${ }^{11}$ This presumably led to significant overestimation of the effectiveness of toric IOLs. In a similar study, Laurendeau et al. ${ }^{10}$ found that lifetime cost savings from a societal perspective ranged from $€ 308$ to $€ 694$ per patient. However, cataract surgery costs were based on diagnosis-related group prices, which were identical for surgery with toric IOL implantation and monofocal IOL implantation. This led to an underestimation of incremental costs of toric IOLs. QALYs were not taken into account.

Previously, we reported the results of a randomized clinical trial (RCT) of distance spectacle independence and quality of vision after bilateral toric IOL versus monofocal IOL implantation in cataract patients with bilateral corneal astigmatism. ${ }^{4}$ In the present study, we performed a costeffectiveness analysis of toric IOLs versus monofocal IOLs from a societal and healthcare perspective using the same patient cohort.

\section{PATIENTS AND METHODS}

This economic evaluation was performed alongside a multicenter RCT that was performed between February 1, 2010, and March 31, 2012, at 3 study centers in the Netherlands. Two study centers (Maastricht University Medical Centre+, Zuyderland Medical Centre Heerlen) participated in the economic evaluation. The study was approved by the institutional review boards of the participating centers. All patients gave written informed consent. The study was performed in accordance with the tenets of the Declaration of Helsinki and good clinical practice guidelines and was registered in a clinical trial register.

\section{Study Procedures}

Study procedures have been described in detail. ${ }^{4}$ In brief, consecutive patients with bilateral age-related cataract and bilateral regular corneal astigmatism of $1.25 \mathrm{D}$ or more were recruited. Furthermore, inclusion in the economic evaluation was based on completion of at least $1 \mathrm{HRQL}$ questionnaire during follow-up. The questionnaire was to be filled in preoperatively and 3 and 6 months postoperatively. Patients who did not complete the questionnaire at either of the postoperative timepoints were excluded from the economic evaluation. Patients were randomized to bilateral implantation of aspheric toric IOLs (Acrysof IQ SN6AT3-T9) or bilateral aspheric monofocal IOLs (Acrysof IQ SN60WF) (both Alcon Laboratories, Inc.). Treatment allocation was concealed until the last follow-up visit. The sample-size calculation was based on distance spectacle independence.

\section{Cost Analysis}

The economic evaluation was performed in accordance with Dutch guidelines. ${ }^{\mathrm{B}}$ Resource-use data were collected over a 6-month period (starting with the day of surgery), both from societal and healthcare perspectives. Costs were calculated by multiplying volumes of resource use with the unit cost price including sales taxes. Costs were converted to 2012 Euros $(€)$ using the Dutch consumer price index. ${ }^{C}$ Costs were also converted to United States dollars using the 2012 purchasing power parity (PPP) for gross domestic product (GDP) $(\$ 1.00=€ 0.829) .{ }^{\mathrm{D}}$

Resource-use data were obtained through hospital registries and self-administered patient questionnaires, which were filled out 3 and 6 months postoperatively. Relevant resources included operating room time, IOL type, hospital daycare admissions, outpatient visits, complications, medication use, general practitioner visits, homecare, spectacles, travel, informal care, and productivity losses. Operating room time was valued using integral cost prices provided by Maastricht University Medical Centre+ and included personnel, materials, and overhead costs. Two costs drivers were applicable, one for general operating room costs (price per minute spent in the operating room) and one for ophthalmology costs (price per minute spent in surgery). Intraocular lenses were valued using actual cost prices. Standardized prices provided by the Dutch guidelines for cost analysis were used to value day-care admissions, outpatient visits, general practitioner visits, homecare, travel, informal care, and productivity loss. ${ }^{\text {B }}$ Costs of spectacles (excluding frames) were obtained through the opticians who provided them. Costs of medication were based on reimbursement prices. ${ }^{\mathrm{E}}$ Complications were treated with medication or surgical procedures and were valued accordingly.

\section{Effectiveness}

Effectiveness was based on HRQL (societal perspective) and clinical outcomes (healthcare perspective). HRQL was determined with the Health Utilities Index Mark 3 (HUI3, Health Utilities Inc.). The HUI3 is a well-validated questionnaire assessing $8 \mathrm{di}-$ mensions of health (vision, hearing, speech, ambulation, dexterity, emotion, cognition, and pain and discomfort). Using a multiplicative multi-attribute utility function, an overall utility score can be derived that ranges from -0.36 (health state worse than death) to 1.00 (perfect health). ${ }^{12}$ Utilities were used to calculate QALYs by determining the area under the curve of subsequent utility measurements, assuming linear changes in utilities over time.

Clinical outcomes included distance spectacle independence, binocular UDVA, and binocular corrected distance visual acuity (CDVA). Distance spectacle independence was assessed using a questionnaire on spectacle use. Patients who reported never using spectacles for distance vision 6 months after surgery were classified as spectacle independent. Binocular UDVA and CDVA were determined according to previously described methods and expressed in logarithm of the minimum angle of resolution (logMAR) notation. ${ }^{4}$

All data were collected during the preoperative visit and 3 months and 6 months after surgery on the first eye.

\section{Statistical Analysis}

Outcomes were analyzed according to the intention-to-treat principle. Incomplete cost and effectiveness data were assumed to be missing at random and imputed using multiple imputation with predictive mean matching (SPSS Statistics, version 22.0 for Windows, IBM Corp.). The linear regression imputation model included treatment group, age, sex, and study center as covariates.

For continuous variables, differences between treatment groups were analyzed with independent samples $t$ tests, while differences between preoperative and postoperative measurements were 
analyzed with paired-sample $t$ tests. Similarly, the Pearson chisquare and McNemar tests were used for discrete variables. A $P$ value less than 0.05 was considered statistically significant.

Cost-effectiveness was estimated by calculating the incremental cost-effectiveness ratio, which expresses the additional costs for each additional unit of the health effect. Bootstrapping with 1000 replications was performed to estimate uncertainty in incremental costs and effects (Excel software, 2010 for Windows, Microsoft Corp.). The results of the bootstrap were plotted in cost-effectiveness planes. In addition, cost-effectiveness acceptability curves were constructed to estimate the probability that either treatment was cost-effective based on a range of ceiling ratios for the incremental cost-effectiveness ratio. These ceiling ratios represent the maximum amount of money health policymakers are willing to pay for an additional unit of the health effect. In the Netherlands, the ceiling ratio for conditions with limited burden of disease, such as spectacle dependence, is $€ 20000$ (\$24 125) per QALY.

\section{Cost-Effectiveness Analyses}

In the base-case analysis, cost-effectiveness was determined using QALYs and costs from a societal perspective over the 6-month follow-up. In a sensitivity analysis, the base-case analysis was repeated with a correction for the imbalance in baseline utility. This correction was performed by adding the mean difference in baseline utility between treatment groups to all utility measurements in the treatment group with the lower baseline.

Secondary analyses were performed using alternative (clinical) effectiveness measures and costs from a healthcare perspective. These measures included distance spectacle independence and a binocular UDVA of $0.10 \operatorname{logMAR}$ or better ( $\geq 20 / 25$ Snellen). Another secondary analysis assessed the expected long-term effect of lower spectacle costs in the toric IOL group. QALYs and costs from a societal perspective were extrapolated to a lifetime time horizon. Life expectancy was determined for each patient based on demographic data. ${ }^{G}$ It was assumed that QALYs remained constant and that spectacle costs were the only recurring costs. Furthermore, spectacles were assumed to be replaced every 4 years in accordance with Dutch market research. ${ }^{\mathrm{H}}$ A scenario analysis was performed to assess the effect of replacing spectacles biannually. All costs incurred more than 1 year after surgery were annually discounted at a rate of $4.0 \%$, while QALYs were discounted at a rate of $1.5 \%{ }^{\mathrm{B}}$

\section{RESULTS}

Two participating centers recruited 82 patients eligible for inclusion in the economic evaluation. Five patients $(6 \%)$ did not complete any HRQL questionnaire postoperatively and were excluded from the economic evaluation. Reasons for not completing questionnaires were death unrelated to the intervention, loss to follow-up after surgery on the first eye, refusal (2 patients), or unknown. As a result, 154 eyes of 77 patients were included in the economic evaluation with 33 patients randomized to the toric IOL group and $44 \mathrm{pa}-$ tients to the monofocal IOL group.

The mean patient age was 73.8 years $\pm 10.2(\mathrm{SD})$ in the monofocal IOL group and $74.2 \pm 7.7$ years in the toric IOL group. The mean preoperative corneal astigmatism was $1.98 \pm 0.83 \mathrm{D}$ (range 0.57 to $5.54 \mathrm{D}$ ) group and $2.03 \pm 0.98 \mathrm{D}$ (range 0.71 to $6.15 \mathrm{D}$ ), respectively, and the mean postoperative corneal astigmatism was $1.98 \pm 0.85$ $\mathrm{D}$ (range 0.28 to $4.97 \mathrm{D}$ ) and $2.04 \pm 0.96 \mathrm{D}$ (range 0.43 to $5.81 \mathrm{D})$, respectively. The mean preoperative refractive astigmatism was $-2.25 \pm 1.21 \mathrm{D}$ (range -6.00 to $0.00 \mathrm{D}$ ) in the monofocal IOL group and $-2.28 \pm 1.19 \mathrm{D}$ (range -7.00 to $-0.50 \mathrm{D}$ ) in the toric IOL group, and the mean postoperative refractive astigmatism was $-1.85 \pm 0.97 \mathrm{D}$ (range -4.50 to 0.00 ) and $-0.75 \pm 0.54 \mathrm{D}$ (range -2.00 to 0.00 ), respectively. The following cost and effectiveness data were missing and imputed: HUI3 6.3\%, distance spectacle use $2.2 \%$, visual acuity $3.0 \%$, costs $8.7 \%$.

\section{Costs}

Table 1 shows the mean resource use and costs per patient. The total costs of bilateral cataract surgery from a societal perspective were $€ 407$ ( $\$ 491)$ higher in the toric IOL group $(€ 3203$ [\$3864]) than in the monofocal IOL group ( $€ 2796[\$ 3373])$. From a healthcare perspective, total costs were $€ 635$ (\$766) higher in the toric IOL group. The resources that contributed most to these differences were operating room costs $(€ 154$ [\$186] higher), price of IOLs $(€ 414$ [\$499] higher), and spectacle costs $(€ 179$ [\$216] lower).

\section{Effectiveness}

Table 2 shows the health-related utilities, spectacle independence, and binocular visual acuity at baseline and 6 months postoperatively. The difference in QALYs was not statistically significant between the toric IOL group and monofocal IOL group $(P=.75)$. Spectacle independence increased significantly more in the toric IOL group than in the monofocal IOL group $(P<.01)$.

\section{Cost-Effectiveness}

Table 3 shows the results of the cost-effectiveness analyses. In the base-case analysis, toric IOL implantation resulted in slightly fewer QALYs and higher costs than monofocal IOL implantation. Toric IOL implantation was therefore inferior to monofocal IOL implantation. The costeffectiveness plane shows that most bootstrapped estimates of incremental costs and QALYs were located in the upper west quadrant (ie, more costly, less effective) (Figure 1). The probability that toric IOLs were cost-effective ranged from $1 \%$ to $15 \%$, assuming the maximum acceptable incremental cost-effectiveness ratio ranged from $€ 2500$ (\$3016) to $€ 20000$ (\$24 125) per QALY (Figure 2).

From a healthcare perspective, the incremental costeffectiveness ratios were $€ 1310$ (\$1580) per spectacle independent patient and $€ 2758$ (\$3327) per patient with binocular UDVA 0.10 logMAR or better ( $\geq 20 / 25$ Snellen). The secondary analysis involving extrapolation of societal costs and QALYs to a lifetime time horizon resulted in higher costs and lower QALYs in the toric IOL group (ie, inferiority).

The sensitivity and scenario analyses did not show contrasting results.

\section{DISCUSSION}

This trial-based economic evaluation assessed the costeffectiveness of bilateral toric IOL implantation versus monofocal IOL implantation in cataract patients with bilateral corneal astigmatism. In the base-case analysis from a 
Table 1. Mean resource use and costs (in $2012 €$ ) from a societal perspective.

\begin{tabular}{|c|c|c|c|c|c|}
\hline \multirow[b]{3}{*}{ Variable } & \multirow[b]{3}{*}{ Cost per Unit $(€)$} & \multicolumn{4}{|c|}{ Mean \pm SE } \\
\hline & & \multicolumn{2}{|c|}{ Resource Use } & \multicolumn{2}{|c|}{ Costs $(€)$} \\
\hline & & Monofocal IOL & Toric IOL & Monofocal & Toric \\
\hline \multicolumn{6}{|l|}{ Healthcare sector } \\
\hline \multicolumn{6}{|l|}{ Operating room } \\
\hline General operating room costs & $11.73 / \mathrm{min}$ & $90.5 \pm 2.68$ & $101.1 \pm 3.67$ & $1061 \pm 31.4$ & $1185 \pm 43.1$ \\
\hline Ophthalmology costs & $3.49 / \mathrm{min}$ & $31.6 \pm 1.06$ & $40.2 \pm 1.22$ & $110 \pm 3.7$ & $140 \pm 4.2$ \\
\hline \multicolumn{6}{|l|}{ Intraocular lens } \\
\hline Monofocal & $96.22 / / O L$ & 2.0 & - & 192 & - \\
\hline Toric & $303.02 / \mathrm{IOL}$ & - & 2.0 & - & 606 \\
\hline Day-care admission & 266.54/day & 2.0 & 2.0 & 533 & 525 \\
\hline Outpatient visits & 136.99/visit & $1.6 \pm 0.33$ & $2.0 \pm 0.62$ & $220 \pm 45.6$ & $271 \pm 84.5$ \\
\hline Complications & Variable & \multicolumn{2}{|c|}{ Variable } & $7 \pm 2.4$ & $63 \pm 31.7^{\star}$ \\
\hline Medication & Variable & \multicolumn{2}{|c|}{ Variable } & $84 \pm 4.3$ & $81 \pm 2.4$ \\
\hline General practitioner visits & 29.73/visit & $0.7 \pm 0.25$ & $0.4 \pm 0.17$ & $20 \pm 7.3$ & $11 \pm 5.0$ \\
\hline Home care & $37.17 / \mathrm{hr}$ & $1.7 \pm 1.04$ & $1.2 \pm 0.72$ & $63 \pm 38.7$ & $45 \pm 26.8$ \\
\hline Subtotal & - & - & - & $2292 \pm 69.7$ & $2927 \pm 104.2$ \\
\hline \multicolumn{6}{|l|}{ Patient and family costs } \\
\hline Spectacles & Variable & \multicolumn{2}{|c|}{ Variable } & $349 \pm 42.6$ & $179 \pm 41.4$ \\
\hline Travel costs & Variable & \multicolumn{2}{|c|}{ Variable } & $16 \pm 5.6$ & $11 \pm 3.8$ \\
\hline Informal care & $13.27 / \mathrm{hr}$ & $4.1 \pm 1.03$ & $2.3 \pm 0.78$ & $55 \pm 13.7$ & $30 \pm 10.3$ \\
\hline Subtotal & - & - & - & $420 \pm 49.3$ & $220 \pm 44.0$ \\
\hline \multicolumn{6}{|l|}{ Other sectors } \\
\hline Productivity costs & Variable & \multicolumn{2}{|c|}{ Variable } & $84 \pm 59.1$ & $55 \pm 51.8$ \\
\hline Total costs from societal perspective & - & - & - & $2796 \pm 108.3$ & $3203 \pm 148.5$ \\
\hline
\end{tabular}

$\mathrm{IOL}=$ intraocular lens; SE $=$ standard error of the mean

${ }^{*}$ One patient had toric IOL repositioning because of IOL rotation

societal perspective, toric IOL implantation was deemed inferior to monofocal IOL implantation (ie, more costly, fewer QALYs). In contrast, patients who received toric IOLs had better postoperative binocular UDVA and were more often distance spectacle independent. However, health policymakers have not defined incremental costeffectiveness ratio threshold values when alternative effectiveness measures are used. ${ }^{\mathrm{F}}$

Table 2. Health-related utilities, spectacle independence, and binocular UDVA and CDVA at baseline and 6 months postoperatively.

\begin{tabular}{|c|c|c|c|}
\hline Variable & Monofocal IOL $(n=44)$ & Toric IOL $(\mathrm{n}=33)$ & Mean Difference \\
\hline \multicolumn{4}{|c|}{ Mean health-related utility \pm SE } \\
\hline Preoperative & $0.56 \pm 0.04$ & $0.52 \pm 0.05$ & $-0.04 \pm 0.07$ \\
\hline Six months postoperative & $0.65 \pm 0.04$ & $0.63 \pm 0.04$ & $-0.02 \pm 0.06$ \\
\hline Mean difference & $0.09 \pm 0.03^{*}$ & $0.11 \pm 0.05^{+}$ & $0.02 \pm 0.06$ \\
\hline Mean QALYs \pm SE & $0.31 \pm 0.02$ & $0.30 \pm 0.02$ & $-0.01 \pm 0.03$ \\
\hline \multicolumn{4}{|l|}{ Spectacle independence, $\mathrm{n}(\%)$} \\
\hline Preoperative & 1 (3) & $3(9)$ & 6 \\
\hline Six months postoperative & $14(32)$ & $27(80)$ & 49 \\
\hline Mean difference & $13(29)^{*}$ & $24(71)^{*}$ & $42^{\ddagger}$ \\
\hline \multicolumn{4}{|c|}{ Mean binocular UDVA (logMAR) \pm SE } \\
\hline Preoperative & $0.58 \pm 0.09$ & $0.54 \pm 0.09$ & $-0.04 \pm 0.13$ \\
\hline Six months postoperative & $0.20 \pm 0.03$ & $0.09 \pm 0.03$ & $-0.11 \pm 0.04^{\ddagger}$ \\
\hline Mean difference & $-0.38 \pm 0.09^{*}$ & $-0.45 \pm 0.08^{*}$ & $-0.07 \pm 0.12$ \\
\hline \multicolumn{4}{|c|}{ Mean binocular CDVA (logMAR) \pm SE } \\
\hline Preoperative & $0.19 \pm 0.02$ & $0.23 \pm 0.03$ & $0.04 \pm 0.04$ \\
\hline Six months postoperative & $-0.01 \pm 0.02$ & $0.02 \pm 0.02$ & $0.03 \pm 0.03$ \\
\hline Mean difference & $-0.20 \pm 0.02^{*}$ & $-0.21 \pm 0.03^{\star}$ & $-0.02 \pm 0.04$ \\
\hline
\end{tabular}

CDVA = corrected distance visual acuity; IOL = intraocular lens; logMAR = logarithm of the minimum angle of resolution; QALYS = quality-adjusted life years; $\mathrm{SE}=$ standard error of the mean; UDVA = uncorrected distance visual acuity

${ }^{\star} P<.01$ for difference between preoperative and postoperative measurement

${ }^{\dagger} P<.05$ for difference between preoperative and postoperative measurement

${ }^{\ddagger} P<.01$ for difference between treatment groups 
Table 3. Results of the cost-effectiveness analyses.

\begin{tabular}{|c|c|c|c|c|c|c|c|}
\hline \multirow[b]{2}{*}{ Parameter } & \multirow{2}{*}{$\begin{array}{c}\text { Mean } \\
\text { Costs }(€)\end{array}$} & \multirow{2}{*}{$\begin{array}{l}\text { Mean } \\
\text { Effects }\end{array}$} & \multirow{2}{*}{$\begin{array}{c}\text { Incremental } \\
\text { Cost-Effectiveness } \\
\text { Ratio }(€)\end{array}$} & \multicolumn{4}{|c|}{ Probability Cost-Effective at Ceiling Ratio (\%) } \\
\hline & & & & $€ 2500$ & $€ 5000$ & $€ 10000$ & $€ 20000$ \\
\hline \multicolumn{8}{|c|}{$\begin{array}{l}\text { Base-case analysis } \\
\text { QALYs and costs from societal } \\
\text { perspective, 6-mo follow-up }\end{array}$} \\
\hline Monofocal IOL & 2796 & 0.31 & - & - & - & - & - \\
\hline Toric IOL & 3203 & 0.30 & Inferior & 1 & 3 & 7 & 15 \\
\hline \multicolumn{8}{|c|}{$\begin{array}{l}\text { Secondary analyses } \\
\text { Spectacle independe } \\
\text { from healthcare } \\
6 \text {-mo follow-up }\end{array}$} \\
\hline Monofocal IOL & 2292 & 0.32 & - & - & - & - & - \\
\hline Toric IOL & 2927 & 0.80 & 1310/pt & 98 & 100 & 100 & 100 \\
\hline \multicolumn{8}{|c|}{$\begin{array}{l}\text { Binocular UDVA } 0.10 \text { logMAR or better } \\
\text { and costs from healthcare } \\
\text { perspective, 6-mo follow-up }\end{array}$} \\
\hline Monofocal IOL & 2292 & 0.33 & & - & - & - & - \\
\hline Toric IOL & 2927 & 0.56 & 2758/pt & 4 & 80 & 92 & 96 \\
\hline \multicolumn{8}{|c|}{$\begin{array}{l}\text { QALYs and costs from societal } \\
\text { perspective, lifetime extrapolation* }\end{array}$} \\
\hline Monofocal IOL & 3319 & 7.64 & - & - & - & - & - \\
\hline Toric IOL & 3456 & 7.03 & Inferior & 25 & 27 & 28 & 28 \\
\hline \multicolumn{8}{|l|}{ Sensitivity analyses } \\
\hline \multicolumn{8}{|c|}{$\begin{array}{l}\text { QALYs, corrected for baseline } \\
\text { utility difference, and costs } \\
\text { from societal perspective, 6-mo } \\
\text { follow-up }\end{array}$} \\
\hline Monofocal IOL & 2796 & 0.31 & - & - & - & - & - \\
\hline Toric IOL & 3203 & 0.32 & 43 028/QALY & 2 & 4 & 15 & 33 \\
\hline \multicolumn{8}{|l|}{ Scenario analysis } \\
\hline \multicolumn{8}{|c|}{$\begin{array}{l}\text { QALYs and costs from societal } \\
\text { perspective, lifetime } \\
\text { extrapolation, spectacles } \\
\text { replaced every } 2 \mathrm{y}\end{array}$} \\
\hline Monofocal IOL & 4191 & 7.64 & - & - & - & - & - \\
\hline Toric IOL & 3889 & 7.03 & 497/QALY & 34 & 32 & 31 & 30 \\
\hline
\end{tabular}

$\mathrm{IOL}=$ intraocular lens; logMAR = logarithm of the minimum angle of resolution; pt = patient; QALYs = quality-adjusted life years; UDVA = uncorrected distance visual acuity

*Life expectancy determined for each patient individually; spectacles replaced every 4 years; costs discounted at a rate of $4 \%$; QALYs discounted at a rate of $1.5 \%$

Previous studies $5,6,8,9$ have found improvements in vision-related quality of life and patient satisfaction after toric IOL implantation. Nonetheless, QALYs are the preferred measure of effectiveness in economic evaluations. In the current study, these were calculated based on a wellvalidated generic HRQL questionnaire; however, no significant difference between treatment groups was found. At the time of inclusion, patients could already obtain toric IOLs through copayment. As a result, patients with a strong preference for toric IOLs, who likely would have had a larger gain in HRQL, might have refused participation in the randomized trial. More important, although the HUI3 is 1 of few HRQL questionnaires that include questions on vision, it might not be responsive enough to detect minor improvements in quality of life resulting from distance spectacle independence. ${ }^{13}$ This limitation is inherent to the use of generic HRQL instruments. Although vision-specific questionnaires might be more responsive to these improvements, they cannot be used to calculate QALYs and are therefore considered unsuitable to support decisions on healthcare resource allocation.

Several study limitations might have influenced the accuracy of the estimated costs. First, because of the study's RCT design, all patients had the same preoperative and postoperative procedures, which reduced the normal variation in resource use between treatment groups. This presumably led to underestimation of incremental costs of toric IOLs. For instance, in a real-life setting, patients having toric IOL implantation would require additional preoperative measurements and more preoperative counseling than patients having monofocal IOL implantation.

Second, the time horizon of the study was only 6 months while the effect of toric IOL implantation on quality of life and costs lasts a lifetime. For this reason, costs and QALYs were extrapolated based on several assumptions, which increased uncertainty about the long-term cost-effectiveness 


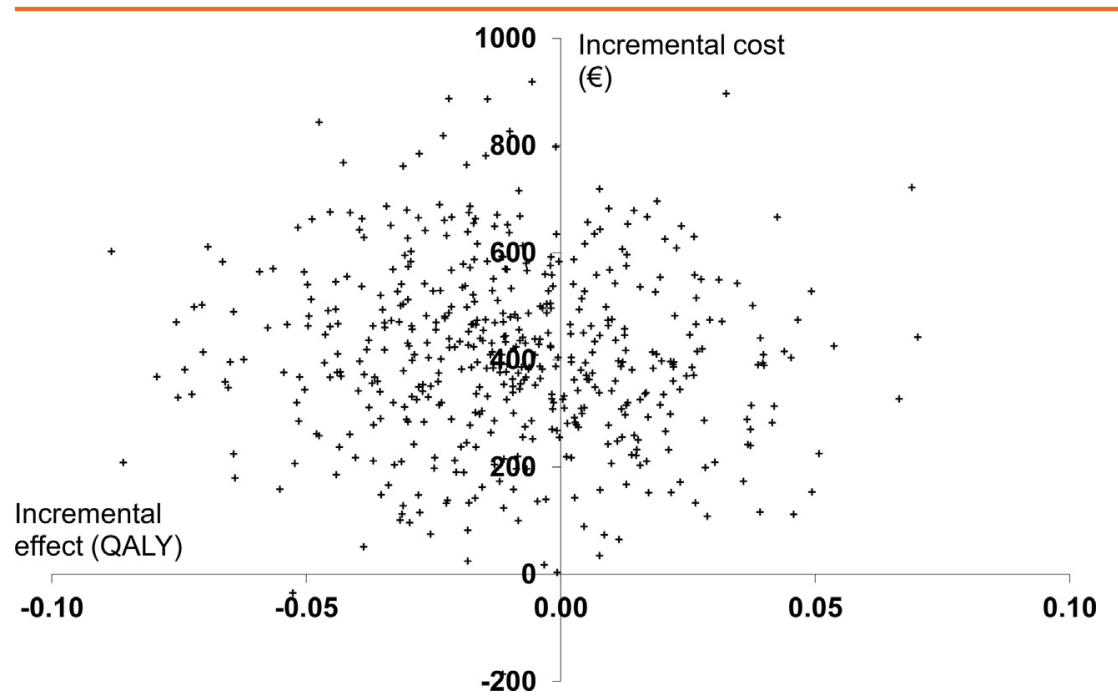

Figure 1. Cost-effectiveness plane showing the incremental costs from a societal perspective and incremental QALYs of treatment with toric IOLs compared with monofocal IOLs within a timeframe of 6 months after cataract surgery. Each datapoint represents 1 bootstrapped estimate of incremental costs and QALYs $(\mathrm{IOLs}=$ intraocular lenses; QALY = qualityadjusted life year).

estimate. Moreover, long-term cost-effectiveness is highly dependent on patient age. Younger patients with a higher remaining life expectancy benefit more from toric IOLs in terms of future cost savings. In the current study, the mean age was 73.8 years in the monofocal IOL group and 74.2 years and toric IOL group. This is comparable to the mean age at which patients have cataract surgery in the Netherlands (73.7 in 2012) and Sweden (74.5 in 2012). ${ }^{14}$

Third, the cataract surgeries in this study took place between 2010 and 2012. In recent years, multiple innovations have occurred that might affect costs in both treatment groups in different ways. For instance, the introduction of digital marking systems for toric IOL alignment might reduce surgical times and enhance the alignment accuracy of toric IOL implantation, thus reducing the number of toric IOL repositioning procedures. ${ }^{15}$

Last, this study used a $1.25 \mathrm{D}$ corneal astigmatism cutoff for inclusion. When this study was designed, we were aware of only 1 previously published randomized trial that compared toric and monofocal IOLs'; the study found that toric IOLs resulted in significantly better UDVA than monofocal IOLs, also in a subgroup analysis of patients with low astigmatism $(0.75$ to $<1.5 \mathrm{D})$. Other studies $^{3,4,9}$

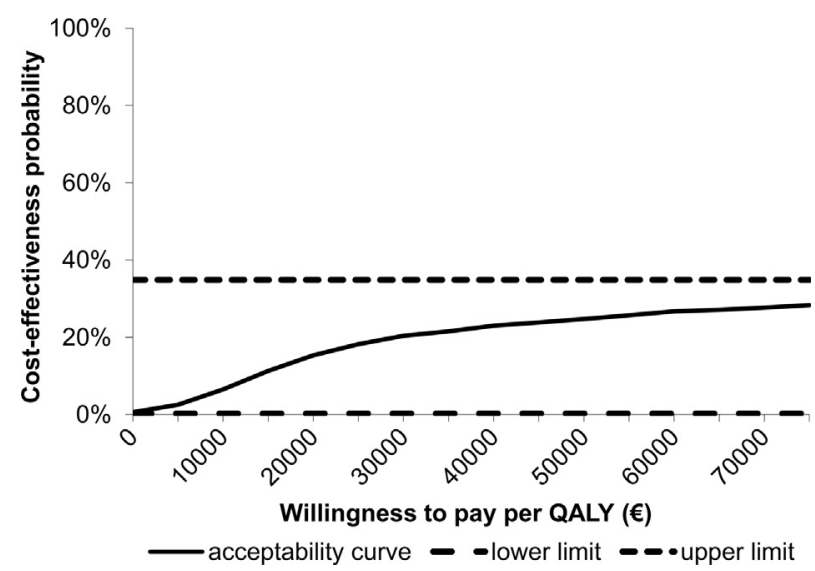

Figure 2. Cost-effectiveness acceptability curve for the incremental costs per QALY gained (from a societal perspective) within a timeframe of 6 months after cataract surgery and treatment with bilateral toric IOLs versus monofocal IOLs (IOLs = intraocular lenses; $\mathrm{QALY}=$ quality-adjusted life year). also found that toric IOLs are effective in achieving better UDVA and lower spectacle dependency compared with monofocal IOLs in patients with astigmatism as low as 0.75 to $1.25 \mathrm{D}$. Nonetheless, a higher corneal astigmatism cutoff for inclusion in the study might have favored postoperative outcomes, including economic outcomes, in the toric IOL group compared with the monofocal IOL group.

A common problem in trial-based cost-effectiveness analyses, including the current study, is that sample sizes are commonly based on clinical outcomes rather than costeffectiveness outcomes. Because there is often considerable variability in resource use and costs, cost-effectiveness analyses typically require significantly larger samples to allow for traditional hypothesis testing. Large samples for the purpose of a cost-effectiveness study might be subject to financial and ethical objections. To overcome these issues, it is now common practice to present results as a cost-effectiveness acceptability curve, which shows the probability of the intervention being cost-effective for a range of ceiling ratios for the incremental cost-effectiveness ratio. ${ }^{16,17}$ Therefore, this study focused on estimating the probability that toric IOLs were cost-effective rather than testing a statistical hypothesis.

The results of an economic evaluation in 1 healthcare system usually cannot be readily translated to another healthcare system. To facilitate transferability of the results, volumes of resource use were reported when possible to enable calculation of costs using local unit prices. Furthermore, the PPP for GDP can be used to convert currencies and adjust for differences in price levels between countries. ${ }^{\mathrm{D}}$

Based on the results of this short-term cost-effectiveness analysis, it can be concluded that cataract surgery with toric IOL implantation is not cost-effective compared with cataract surgery with monofocal IOL implantation. The aim of economic evaluations is to support health policymakers in allocating limited healthcare resources and not to deny individual patients access to an effective treatment. Indeed, patients in the toric IOL group had better binocular UDVA and were more often spectacle independent, which can be of significant value to some individuals. Therefore, copayment should be considered an alternative means of financing toric IOLs so as not to burden national healthcare budgets. 


\section{WHAT WAS KNOWN}

- Compared with monofocal IOL implantation, toric IOL implantation during cataract surgery improves UDVA and spectacle independence in patients with corneal astigmatism. This in turn improves patient satisfaction and visionrelated quality of life.

- Toric IOLs are also associated with increased healthcare costs.

\section{WHAT THIS PAPER ADDS}

- Although this study confirmed that toric IOLs improve UDVA and spectacle independence compared with monofocal IOLs, no improvement in generic health-related quality of life was found. Furthermore, toric IOLs increased healthcare and societal costs in the short-term.

- Compared with monofocal IOLs, toric IOLs were not costeffective from a societal perspective.

\section{REFERENCES}

1. Kessel L, Andresen J, Tendal B, Erngaard D, Flesner P, Hjortdal J. Toric intraocular lenses in the correction of astigmatism during cataract surgery; a systematic review and meta-analysis. Ophthalmology 2016; 123:275286

2. Holland E, Lane S, Horn JD, Ernest P, Arleo R, Miller KM. The AcrySof toric intraocular lens in subjects with cataracts and corneal astigmatism; a randomized, subject-masked, parallel-group, 1-year study. Ophthalmology 2010; 117:2104-2111

3. Waltz KL, Featherstone K, Tsai L, Trentacost D. Clinical outcomes of TECNIS toric intraocular lens implantation after cataract removal in patients with corneal astigmatism. Ophthalmology 2015; 122:39-47

4. Visser N, Beckers HJM, Bauer NJC, Gast STJM, Zijlmans BLM, Berenschot TTJM, Webers CA, Nuijts RMMA. Toric vs aspherical control intraocular lenses in patients with cataract and corneal astigmatism; a randomized clinical trial. JAMA Ophthalmol 2014; 132:1462-1468

5. Lane SS, Ernest P, Miller KM, Hileman KS, Harris B, Waycaster CR. Comparison of clinical and patient-reported outcomes with bilateral AcrySof toric or spherical control intraocular lenses. J Refract Surg 2009; 25:899-901

6. Zhang J-S, Zhao J-Y, Sun Q, Ma L-W. Distance vision after bilateral implantation of AcrySof toric intraocular lenses: a randomized, controlled, prospective trial. Int J Ophthalmol 2011; 4:175-178

7. Pineda R, Denevich S, Lee WC, Waycaster C, Pashos CL. Economic evaluation of toric intraocular lens; a short- and long-term decision analytical model. Arch Ophthalmol 2010; 128:834-884

8. Mencucci R, Giordano C, Favuzza E, Gicquel JJ, Spadea L, Menchini U. Astigmatism correction with toric intraocular lenses: wavefront aberrometry and quality of life. Br J Ophthalmol 2013; 97:578-582

9. Ahmed IIK, Rocha G, Slomovic AR, Climenhaga H, Gohill J, Grégoire A, Ma J, for the Canadian Toric Study Group. Visual function and patient experience after bilateral implantation of toric intraocular lenses. J Cataract Refract Surg 2010; 36:609-616

10. Laurendeau C, Lafuma A, Berdeaux G. Modelling lifetime cost conse quences of toric compared with standard IOLs in cataract surgery of astigmatic patients in four European countries. J Med Econ 2009; 12:230-237

11. Drummond MF, Sculpher MJ, Claxton K, Stoddart GL, Torrance GW Methods for the Economic Evaluation of Health Care Programmes, 4th ed. Oxford, UK, Oxford University Press, 2015; 124-143

12. Horsman J, Furlong W, Feeny D, Torrance G. The Health Utilities Index $\left(H \cup I^{\circledR}\right)$ : concepts, measurement properties and applications. Health Qual Life Outcomes 2003; 1:54

13. Blumberg DM. Value of primary data in cost-effectiveness analyses [invited commentary]. JAMA Ophthalmol 2018; 136:532-533

14. Lundström M, Goh P-P, Henry Y, Salowi MA, Barry P, Manning S, Rosen P Stenevi $\cup$. The changing pattern of cataract surgery indications; a five-year study of two cataract surgery databases. Ophthalmology 2015; 122:31-38

15. Webers VSC, Bauer NJC, Visser N, Berendschot TTJM, van den Biggelaar FJHM, Nuijts RMMA. Image-guided system versus manual marking for toric intraocular lens alignment in cataract surgery. J Cataract Refract Surg 2017; 43:781-788

16. Petrou S, Gray A. Economic evaluation alongside randomised controlled trials: design, conduct, analysis, and reporting. BMJ 2011; 342:d1548

17. O'Sullivan AK, Thompson D, Drummond MF. Collection of health-economic data alongside clinical trials: is there a future for piggyback evaluations? Value Health 2005; 8:67-79

\section{OTHER CITED MATERIAL}

A. U.S. National Institutes of Health Clinical Trials. Astigmatism Management in Cataract Surgery With the AcrySof Toric Intraocular Lens. NCT01075542. Available at: https://clinicaltrials.gov/ct2/show/NCT01075542. Accessed October 6, 2018

B. Hakkaart-van Roijen L, Tan SS, Bouwmans CAM. Handleiding voor kostenonderzoek: methoden en standaard kostprijzen voor economische evaluaties in de gezondheidszorg. Diemen, the Netherlands. College voor Zorgverzekeringen, 2011

C. Centraal Bureau voor de Statistiek. Consumer prices; price index $1900=$ 100. Den Haag, the Netherlands, 2018. Available at: http://statline.cbs.nl /Statweb/publication/?DM $=$ SLEN\&PA $=71905 E N G \& D 1=0 \& D 2=0,10,20$ ,30,40,50,60,63,70,80,90,100-I\&LA=EN\&WW=T. Accessed October 6, 2018

D. Organisation for Economic Co-operation and Development. Purchasing Power Parities for GDP and related indicators. Available at: http://stats.oecd .org/Index.aspx?DataSetCode=PPPGDP. Accessed October 6, 2018

E. Zorginstituut Nederland. Medicijnkosten. Available at: https://www .medicijnkosten. nl. Accessed October 6, 2018

F. Zwaap J, Knies S, van der Meijden C, Staal P, van der Heiden L. Rapport kosteneffectiviteit in de praktijk. Diemen, the Netherlands, Zorginstituut Nederland, 2015. Available at: https://www.zorginstituutnederland.nl/publicaties /rapport/2015/06/26/kosteneffectiviteit-in-de-praktijk. Accessed October 6, 2018

G. Centraal Bureau voor de Statistiek. Prognose levensverwachting geslacht en leeftijd, 2012-2060. Den Haag, the Nethrlands, 2018. Available at: http://statline.cbs.nl/Statweb/publication/?DM=SLNL\&PA $=81630 \mathrm{NED} \& \mathrm{D} 1=3 \& \mathrm{D} 2=\mathrm{a} \& \mathrm{D} 3=\mathrm{a} \& \mathrm{D} 4=0 \& \mathrm{HDR}=\mathrm{T} \& \mathrm{STB}=\mathrm{G} 1, \mathrm{G} 2, \mathrm{G} 3$ $\& \mathrm{~W}=\mathrm{T}$. Accessed October 6, 2018

H. Terra J, Q\&A Research \& Consultancy. Optiektrends 2020, ontwikkelingen in consumentengedrag. Den Haag and Woerden, the Netherlands, Hoofdbedrijfschap Detailhandel \& Nederlandse Unie van Optiekbedrijven, 2011. Available at: https://www.nuvo.nl/websites/nuvo/files/Optiek/Onderzoek \%20en\%20cijfers/2011-08-08\%200ptiektrends\%20QnA\%202020.pdf. Accessed October 6, 2018

Disclosures: Dr. Nuijts is a consultant to Alcon Laboratories, Inc., Asico LLC, and Théa Pharma GmbH; receives financial support for research from Acufocus, Inc., Alcon Laboratories, Inc., Bausch \& Lomb, Inc., Gebauer Medizintechnik GmbH, Humanoptics $A G$, and Ophtec BV; and receives lecture fees from Alcon Laboratories, Inc. Dr. Webers is a consultant to Alcon Laboratories, Inc., Allergan, Inc., and Santen $\mathrm{GmbH}$; receives financial support for research from Alcon Laboratories, Inc. and Santen $\mathrm{GmbH}$; and receives lecture fees from Alcon Laboratories, Inc. Théa Pharma GmbH, and Santen $\mathrm{GmbH}$. Dr. Bauer is a consultant to Alcon Laboratories, Inc., and Bausch \& Lomb, Inc.; receives financial support for research from Alcon Laboratories, Inc. and Physiol S.A.; and receives lecture fees from Alcon Laboratories, Inc. and Bausch \& Lomb, Inc. Dr. Beckers is a consultant to Alcon Laboratories, Inc.; receives financial support for research from Alcon Laboratories, Inc., Allergan/Aquesys, Glaukos Corp., and InnFocus, Inc.; and receives lecture fees from Alcon Laboratories, Inc., Allergan, Inc./Aquesys, Inc., Santen GmbH, and Merck Sharp \& Dohme Corp. None of the other authors has a financial or proprietary interest in any material or method mentioned.

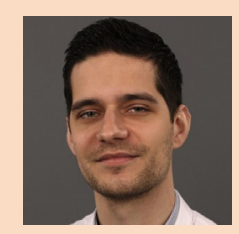

First author: Rob W.P. Simons, MD University Eye Clinic Maastricht, Maastricht University Medical Centre +, Maastricht the Netherlands 